\title{
IMPERFECT COMPETITION IN CHINA'S IMPORT MARKET OF ROUNDWOOD AND LUMBER PRODUCTS
}

\author{
CHANGYOU SUN* \\ Department of Forestry, Mississippi State University, Mississippi State, Mississippi \\ XIAOPING ZHOU \\ Pacific Northwest Research Station, U.S. Forest Service, Portland, Oregon
}

\begin{abstract}
China has become the largest importer of roundwood and lumber products in recent years. In this study, the degree of competition among major supplying countries in China's import market is measured through the inverse residual demand elasticity over 1995-2015. Time-series properties of the data are considered through the autoregressive distributed lag model. The analysis reveals that market power exists in roundwood and lumber markets for a few supplying countries. The suppliers in the lumber import market have more market power than those in the roundwood market. Individual countries with substantial market power have more fluctuations in trading volumes.
\end{abstract}

Keywords. Autoregressive distributed lag model, bounds test, error correction model, inverse residual demand elasticity, market power

JEL Classifications. C32, F12, L73, Q23

\section{Introduction}

China has become a leading participant in the global wood products market since the 1990s. Given its limited forest resources per capita, domestic wood fiber supply in China is insufficient relative to the demand. Participation in the international market by China has been realized through importing raw materials and then exporting finished wood products. Raw materials include both roundwood (also referred to as unprocessed timber, sawlog, or $\log$ ) and lumber (or sawnwood) products. In fact, China's imports of roundwood and lumber products have been more than $30 \%$ and $20 \%$ of world total in recent years, respectively (Food and Agriculture Organization of the United Nations, 2016). From 2011 to 2015, China's total annual spending on roundwood and

The study was financially supported by the U.S. Department of Agriculture, Forest Service, Pacific Northwest Research Station under agreement 15-JV-11261975-024.

*Corresponding author's e-mail: cs258@msstate.edu 
Table 1. Supplying Countries, Average Annual Import Values, and Market Shares by Product over 2011-2015

\begin{tabular}{|c|c|c|c|c|c|c|c|}
\hline Item & Product & Total & Top Four & First & Second & Third & Fourth \\
\hline \multicolumn{8}{|c|}{ Source } \\
\hline & 440320 & World & & Russia & New Zealand & United States & Canada \\
\hline & 440399 & World & & Papua New Guinea & Solomon Islands & Laos & Myanmar \\
\hline & 440710 & World & & Canada & Russia & United States & Chile \\
\hline & 440799 & World & & Thailand & United States & Russia & Indonesia \\
\hline \multicolumn{8}{|c|}{ Value } \\
\hline & 440320 & 28.4 & 25.3 & 8.7 & 8.4 & 5.3 & 2.9 \\
\hline & 440399 & 20.7 & 9.6 & 3.4 & 2.5 & 2.1 & 1.6 \\
\hline & 440710 & 21.0 & 18.3 & 8.3 & 7.7 & 1.2 & 1.1 \\
\hline & 440799 & 12.9 & 8.7 & 5.2 & 1.8 & 0.9 & 0.8 \\
\hline \multicolumn{8}{|c|}{ Share } \\
\hline & 440320 & $100 \%$ & $90 \%$ & $31 \%$ & $30 \%$ & $19 \%$ & $10 \%$ \\
\hline & 440399 & $100 \%$ & $46 \%$ & $16 \%$ & $12 \%$ & $10 \%$ & $8 \%$ \\
\hline & 440710 & $100 \%$ & $88 \%$ & $40 \%$ & $37 \%$ & $6 \%$ & $5 \%$ \\
\hline & 440799 & $100 \%$ & $67 \%$ & $40 \%$ & $14 \%$ & $7 \%$ & $6 \%$ \\
\hline
\end{tabular}

Notes: The first panel reports supplying country names in the import market of roundwood and lumber products in China. The second panel contains average import values in billion Chinese yuan from 2011 to 2015. The average exchange rate between China and the United States is about 6.3 Chinese yuan per U.S. dollar over this period (International Monetary Fund, 2016). Thus, 28.4 billion Chinese yuan is approximately equal to 4.5 billion U.S. dollars. The third panel reports the corresponding shares in the import market of China. The four products are Harmonized Tariff Schedule (HTS) 440320 coniferous roundwood, HTS 440399 nonconiferous roundwood, HTS 440710 coniferous lumber, and HTS 440799 nonconiferous lumber. The data are collected from Global Trade Information Services (2016).

lumber imports reached 13.2 billion U.S. dollars (Table 1). Combined with its strong manufacturing capacity, China has exported an increasing volume of wood-based panels (i.e., particleboard) and furniture products worldwide.

Several supplying countries have demonstrated some dominance in China's import markets of individual wood products. In the coniferous roundwood market, Russia has been the leading supplier, with an average market share of 31\% over 2011-2015 (Global Trade Information Services, 2016). In recent years, New Zealand, the United States, and Canada also have supplied more roundwood, with the corresponding market shares of $30 \%, 19 \%$, and $10 \%$. The nonconiferous roundwood market has been more diverse. From 2011 to 2015, the top four suppliers are Papua New Guinea (16\%), Solomon Islands $(12 \%)$, Laos $(10 \%)$, and Myanmar $(8 \%)$. The coniferous lumber market is dominated by Canada $(40 \%)$ and Russia $(37 \%)$, whereas the leading suppliers in the nonconiferous lumber market are Thailand $(40 \%)$ and the United States (14\%) from 2011 to 2015 (Table 1). Overall, the concentration is higher in the softwood market than in the hardwood market, with the share of the top four suppliers being $90 \%$ for the coniferous roundwood market. 
A few studies have analyzed China's import demand for roundwood and lumber products. For instance, Turner et al. (2005) assessed the impact of removing tariff and nontariff barriers on New Zealand's export of wood products to China. Zhang and $\mathrm{Li}(2009)$ used a gravity model for investigating determinants of China's wood products trade from 1995 to 2004. Niquidet and Tang (2013) examined the roundwood and lumber imports by China and Japan. Sun (2014) assessed China's roundwood import demand by supplying source and product type between 1995 and 2012. Despite all those efforts, little research has been conducted to empirically evaluate the competitiveness of the import markets of roundwood and lumber in China. Given the large volume of raw wood products imported by China, there have been critical needs to examine the interaction among the dominant suppliers in the markets.

The objective of this study is to measure the degree of competition among major supplying countries and identify their potential market power in China's import market of roundwood and lumber products. The assessment is conducted for three individual markets: coniferous roundwood, coniferous lumber, and nonconiferous lumber. Within each import market in China, the top four supplying countries are included (e.g., Russia, New Zealand, the United States, and Canada) for the coniferous roundwood. Recent tools developed in the industrial organization literature and time-series econometrics are integrated into the assessment. Inverse residual demand elasticity is calculated for each product-supplier pair. The time-series properties of the data are addressed within the framework of autoregressive distributed lag (ARDL) model. In particular, the ARDL framework developed by Pesaran, Shin, and Smith (2001) will be combined with the residual demand model in this study. The advantage of the ARDL framework is that it does not depend on the integration orders of the variables, and thus it eliminates the uncertainty associated with pretesting the order of integration in other cointegration methods. The findings from this study will be helpful for supplying countries to comprehend the competition in the import market of China.

\section{Methodology}

The methods employed in this study involve two strands of the literature. One is related to the theoretical and empirical model specifications, and the other is relevant to the estimation method. Both strands of the literature are sophisticated and extensive. As the current study is an applied empirical analysis and space is limited here, these methods will be briefly described in this section. Some technical details about the estimation method are presented in the Appendix. For a complete description of the methods, interested readers are referred to the corresponding literature, as cited subsequently.

In the following presentation, the structure of a theoretical model for measuring the competition intensity in international trade will be laid out first. 
The residual demand approach, as developed in Baker and Bresnahan (1988) and Goldberg and Knetter (1999), has been widely adopted for assessing the degree of competition in international market (Reed and Saghaian, 2004; Song et al., 2009; Xie and Zhang, 2014). In the present study, this approach is adopted to examine the import market of three wood products: coniferous roundwood, coniferous lumber, and nonconiferous lumber. For each product, four leading suppliers in China's import market are covered. In total, there are 12 product-supplier pairs, and each pair is analyzed separately. One pair is used in the following illustration (i.e., coniferous roundwood export from Russia to China, with the competing countries of New Zealand, the United States, and Canada).

The model derived from the residual demand approach can be estimated by the ordinary least square (OLS) method (e.g., Reed and Saghaian, 2004). However, data used in this type of analysis are time series, and the properties of these data need to be addressed explicitly. One major challenge of doing that is that individual series used in the analysis can have mixed orders of integration. For example, a quantity series can be integrated of order one, but a price series can be stationary. In this study, the framework of the ARDL model as developed by Pesaran, Shin, and Smith (2001) is used to incorporate the properties of such data into the analysis. The ARDL framework has been used in analyzing several issues in agricultural economics, such as price transmission in the grain market (Getnet, Verbeke, and Viaene, 2005), exchange rate effect on trade balance (Baek, Koo, and Mulik, 2009), and sugar confectionery exports (Fedoseeva, 2013).

\subsection{Inverse Residual Demand Elasticity and Competition Intensity}

Goldberg and Knetter (1999) developed an approach to estimate the elasticity of inverse residual import demand of a supplier to detect its market power. The empirical model is derived from specifying the demand and supply system of a selected supplier and other competitors, assuming profit maximization, making a series of operations, and finally reducing the system to a single residual demand function for the supplier (Goldberg and Knetter, 1999). The inverse residual demand function can explain the variation in import price with three observable arguments: the import quantity of a supplier, cost shifters of several rival suppliers, and some demand shifter in the destination market. ${ }^{1}$ For the roundwood imports by China from Russia in this study, the model can be adapted as follows:

$$
p_{t}=\pi_{0}+\pi_{1} q_{t}+\pi_{2} \mathbf{w}_{\mathbf{t}}+\pi_{3} z_{t}+u_{t}
$$

where $p$ and $q$ are the price (Chinese yuan per cubic meter) and quantity of coniferous roundwood imported by China from Russia, respectively; w is the

1 To emphasize, the empirical specification in equation (1) is not an ad hoc demand specification without any consideration of supply. In fact, the specification adopted here is the result of a series of operations on a supply and demand system, as developed by Goldberg and Knetter (1999). The derivation is too long to be replicated here. Interested readers are referred to their study for a complete documentation or Reed and Saghaian (2004) for a summary. 
cost vector of competitors (i.e., New Zealand, the United States, and Canada in this particular case); $z$ is the demand shifter in China, which is represented by the total import and export value of China; $u$ is the error term; and $\pi$ 's are the parameters to be estimated. ${ }^{2}$ The index of $t$ is for monthly data from January 1995 to December 2015. The price, cost shifter, and demand shifter are all deflated by the consumer price index in China, given that the study period is over two decades and quite long. In practice, this function is usually estimated in double log form, so all the variables are first transformed by taking the natural logarithm. Note that only the cost shifters of the competing suppliers are included in the specification. Excluding the cost shifter of the supplying country per se (i.e., Russia in this case) allows identifying the residual demand curve in the derivation, which is an essential feature and treatment of this approach (Goldberg and Knetter, 1999).

The exchange rate between two countries can serve as an ideal cost shifter in an international setting. The fluctuation in exchange rates can be treated as exogenous shocks that shift the production cost of the supplier relative to other competitors in the market. Thus, the cost of competitors is approximated by the exchange rates in this study, measured in the unit of the Chinese yuan for the currency of a competitor (e.g., Canadian dollar per Chinese yuan). The demand shifter can be represented by a time trend, real income (Goldberg and Knetter, 1999), trade volume (Felt, Gervais, and Larue, 2011), the price level of a destination market (Reed and Saghaian, 2004), or a combination of them. In this study, several measures, including gross domestic product and total trade value of China, were considered in the preliminary analysis, and they generated similar results. Imported roundwood and lumber products by China have been used to meet the final demand of wood products (e.g., furniture and wood-based panels) in both domestic and international markets. Thus, China's total trade value (i.e., the sum of import and export) of all commodities over the study period is selected in the end to represent the demand shifter.

The parameter for the quantity variable is the key output. Given the logarithmic specification, it can be directly interpreted as the inverse residual demand elasticity. ${ }^{3}$ It reveals how much influence the supplier has on the market price, taking into account the interaction with other firms in the market. In general, the estimate is expected to be negative. A zero estimate indicates perfect

2 In the preliminary analysis, a dummy variable was added to the regression to account for the roundwood export tax imposed by Russia or global economic recession after 2008. The dummy variable would measure the potential impact of these events on the price, not the demand quantity directly. Preliminary analysis generated very few significant estimates for this variable. An additional independent variable rapidly increases the burden of estimating the model within the ARDL framework. Thus, the dummy variable was dropped from the final specification.

3 Equation (1) is the inverse residual demand function, so the estimate for the coefficient of the quantity variable is the inverse residual demand elasticity. That was explicitly emphasized in Goldberg and Knetter (1999) and Felt, Gervais, and Larue (2011). 
competition, and the supplier faces a perfectly elastic curve. The import price does not depend on the quantity but is entirely determined by the costs of other competitors. The larger the absolute value, the bigger the deviation from marginal cost pricing and thus more market power the supplier exercises. If the estimate is significantly positive, it has been interpreted as no market power either, as discussed in Goldberg and Knetter (1999).

The quantity variable in the model may be endogenous, which can be addressed using the Hausman test and instrument variable (Henneberry and Mutondo, 2009; Kennedy, 2008). Valid instruments in this context are the cost shifter for the supplier of interest, because it is excluded from the estimating equation but is correlated with the quantity variable. Measures of input prices in the supplying country, as well as the exchange rate between the supplying country and the destination market, are ideal instruments too. In this study, the instruments selected are the exchange rate between a supplying country and China and the interest rate in the supplying country. These instruments, along with the exogenous variables in each equation, are used to implement the Hausman test. If there is endogeneity in a model, the predicted value of the quantity can be substituted and utilized in the final estimation.

\subsection{The ARDL Framework}

From the perspective of time-series econometrics, the empirical model in equation (1) is static in nature. A static model focuses on the long-run behavior and ignores any possible dynamic adjustment in the short run. In reality, international trade can be influenced by various factors such as price fluctuations, and thus the market can be out of equilibrium temporarily. To address the limitations of the static model, cointegration and different dynamic short-run models have been developed over time. In this study, the ARDL model and related techniques are employed to capture the dynamics of the adjustment process in the import demand market of China.

In general, the ARDL model with the $(M, N)$ specification can be expressed as follows:

$$
y_{t}=\alpha+\sum_{m=1}^{M} \gamma_{m} y_{t-m}+\sum_{j=1}^{J} \sum_{n=0}^{N_{j}} \beta_{j, n} x_{j, t-n}+\varepsilon_{t}
$$

where $y$ is the dependent variable (i.e., $p$ in this study), and $x$ represents the independent variables (i.e., $q, \mathbf{w}$, and $z$ ). For the indexes, $M$ is the maximum lag for the dependent variable, $J$ is the total number of individual independent variables, $N_{j}$ is the maximum lag for variable $x_{j}$, and $t$ is time. The Greek letters $\alpha, \gamma$, and $\beta$ are coefficients to be estimated. Some of the explanatory variables $x_{j}$ may have no lagged terms in the model (i.e., $N_{j}=0$ ). These variables are called static or fixed regressors. Explanatory variables with at least one lagged term are 
called dynamic regressors. Apparently, equation (2) can accommodate equation (1) as a particular case without any lags.

In recent years, the ARDL model has gained new power within the framework developed by Pesaran, Shin, and Smith (2001). The approach is collectively called the ARDL framework, and the implementation has four major steps (Pesaran and Pesaran, 2009). The first step is to examine the stationarity of individual time series. The augmented Dickey-Fuller test can be used to determine the order. Variables can be all stationary, nonstationary with the order of one, or mixed. The only requirement from the ARDL framework is that none of the variables are integrated of two or higher.

The second step is the bounds test for cointegration analysis. It is designed to determine if there exists any long-run relationship and cointegration among variables in the equation. The bounds test is based on the OLS estimation of an unrestricted error correction model as transformed from equation (2). The existence of a cointegrating relation among $y$ and $x$ is assessed through the F-test for the joint significance of several variables, with critical values from Pesaran, Shin, and Smith (2001).

The bounds test for cointegration is the core of the ARDL framework. This test has several advantages over other cointegration methods (e.g., the two-step procedure by Engle and Granger [1987]). It does not depend on the integration orders of the variables, and the only requirement is that none of the variables are integrated of two or higher. Thus, the bounds test eliminates the uncertainty associated with pretesting the order of integration. Furthermore, the test has better statistical properties than the Engle-Granger method, because it utilizes the unrestricted error correction model and does not constrain the short-run dynamics within the residual term only (Banerjee et al., 1993).

The third step is to identify the ARDL model with the best fit after a long-run cointegrating relation is established for the variables in the equation. All possible combinations of $M$ and $N$ in equation (2) are considered, and the best fit is selected by the Akaike information criterion (AIC). This step involves a large amount of estimation and is time-consuming, as described in the Appendix.

The fourth step is to calculate the long-run and short-run inverse residual demand elasticities from the best-fitted ARDL model to characterize market dynamics. The long-run elasticities are computed from the coefficient estimates from the ARDL model directly. The short-run elasticities are calculated using the restricted error correction model. The standard errors of all the estimates are computed by the delta method.

\section{Data Sources and Software}

Trade data are downloaded from the database offered by Global Trade Information Services (2016). Several specifications are needed to download the 
data: product, country, and time coverage. Three products are defined by the Harmonized Tariff Schedule (HTS) and included in the regression analysis. They are HTS 440320 for coniferous roundwood, 440710 for coniferous lumber, and 440799 for nonconiferous lumber. HTS 440349 for nonconiferous roundwood was excluded in the analysis because of data constraints on the exchange rates of the top suppliers. The exchanges rates of the top supplying countries (e.g., Laos and Myanmar) are fixed or controlled by the governments, resulting in little variation in the time-series data for these countries. For each of the three products included in the study, the top four supplying countries are selected based on their average annual market shares from 2011 to $2015 .{ }^{4}$ The countries selected are Russia, New Zealand, the United States, and Canada for 440320; Canada, Russia, the United States, and Chile for 440710; and Thailand, the United States, Russia, and Indonesia for 440799.

The study period is from January 1995 to December 2015. The end period of 2015 reflected data availability when all the data for this study were downloaded. For each product and supplier, both the import value and quantity by China are downloaded. The ratio of value to quantity is used as the price.

Monthly exchange rates for all the suppliers are measured in China's currency (e.g., Canadian dollar per Chinese yuan). Interest rates are defined as the lending rate of the central bank in a country. The consumer price index in China is used to measure price level in China, with the index value of 100 for 2010. It is used to deflate the variables of price, cost shifter, and demand shifter, as defined in equation (1). All these data are collected from the database maintained by the International Monetary Fund (2016). In addition, China's total trade value of all commodities over the study period is used to represent the demand in China's import market. These monthly trade data are collected from the database maintained by the National Bureau of Statistics of China (2016).

All the analyses in this study are conducted with the software $\mathrm{R}(\mathrm{R}$ Development Core Team, 2017). Several new functions are created to carry out the proposed statistical analyses and draw the figures, and they make the whole analysis more efficient. The results are comparable with those generated from the software EViews 9.5 and Microfit 5.0. In particular, estimating the ARDL model with various specifications is very time-consuming, so parallel computing in $\mathrm{R}$ is incorporated into the new $\mathrm{R}$ functions to facilitate the estimation.

4 Using the whole study period of 1995-2015 will generate a slightly different list of countries. A few countries were major suppliers in the 1990s by market share, but they have become minor suppliers in recent years (e.g., Malaysia in the nonconiferous lumber market). Thus, to make the analysis more current, trade values over 2011-2015 were used in the selection. 

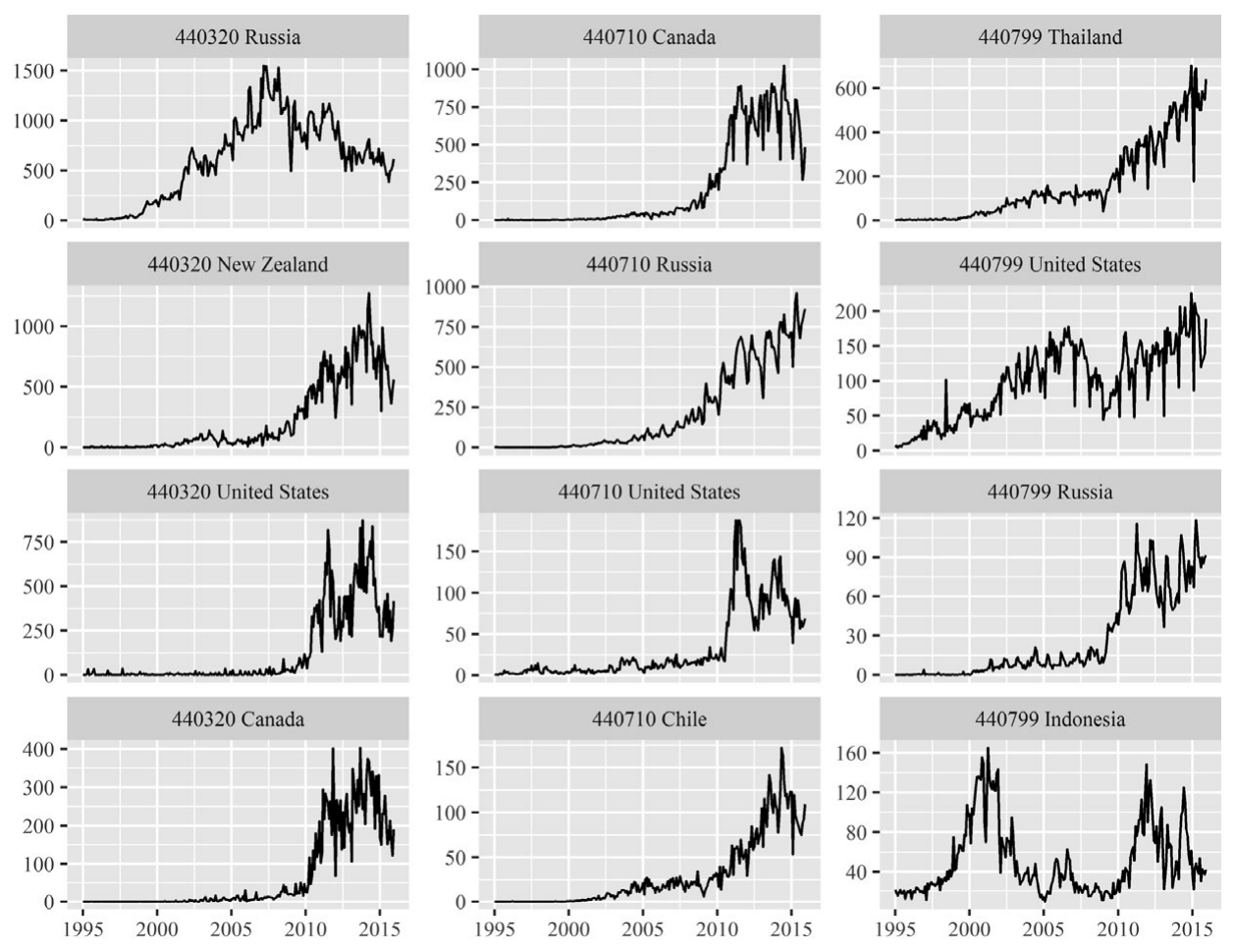

Figure 1. Monthly Roundwood and Lumber Import Values by China from Individual Supplying Countries over 1995-2015 (unit: million Chinese yuan; Harmonized Tariff Schedule [HTS] 440320, coniferous roundwood; HTS 440710, coniferous lumber; and HTS 440799, nonconiferous lumber)

\section{Empirical Results}

\subsection{Trade Patterns over 1995-2015}

The nominal import values by product and source from 1995 to 2015 are presented in Figure 1. In total, there are 12 product-supplier pairs. The general trend is that the trading values were small during the first few years in the 1990s, grew fast until 2008, and then remained steady or declined slightly after that. China joined the World Trade Organization in 2001, and international trade of wood products expanded fast after that. One exception is that China imported a considerable amount of nonconiferous lumber from Indonesia around 2001, as high as 160 million Chinese yuan per month. Across the three product categories, the trading value is the largest for HTS 440320 coniferous roundwood, followed by 440710 coniferous lumber and then 440799 nonconiferous lumber. That is consistent with the summary statistics reported in Table 1. 
Within the overall rising trend, there is a wide variation of the imports from individual supplying countries. In the coniferous roundwood market, the import value from Russia reached its peak around 2007 and then declined moderately, mainly because of its tax on roundwood export (Chang and Gaston, 2016). New Zealand filled a big portion of the market gap left by Russia after 2008 and has become the top supplier in China's import market in recent years. The United States and Canada also have exported a large volume of coniferous roundwood to China since 2011. For coniferous lumber, Canada, Russia, and Chile all have shipped an increasing amount of wood to China since 2006. The United States exported the most around 2011 and then experienced some considerable variation. For nonconiferous lumber, Thailand, the United States, and Russia all have increasing volumes, and Thailand also has the steadiest growth over time. The exception is Indonesia, which had two large peaks around 2001 and 2011 and thus experienced the greatest fluctuation within a decade.

\subsection{Cointegrating Relation and Optimal Lag Selection}

In the beginning, the augmented Dickey-Fuller test is used to examine the stationarity properties of all the time series. Some of the series are nonstationary, but none of them are integrated of order two or above. The Hausman test is used to assess the endogeneity of the quantity variable in each equation. Among the 12 product-supplier pairs, 10 of them show endogeneity, and thus the quantity variables are replaced by the predicted values from the auxiliary regressions. The two exceptions are the export of coniferous lumber from Canada and Chile, and their quantities are used in the analysis without any adjustment.

Within the ARDL framework, the bounds test is employed to determine if a long-run cointegrating relation exists among the economic variables. The $F$-statistic is calculated based on the unrestricted error correction model, derived from the ARDL specification. Initially, the maximum lags for the dependent and dynamic regressors are specified at four (i.e., $M=N=4$ ). Then the statistical properties of the estimated model are assessed through several diagnostic tests. In particular, 2 of the 12 product-supplier pairs need more lags to eliminate the serial correlation in the residual, and they are the coniferous roundwood export from New Zealand and the nonconiferous lumber export from the United States. In the end, six lags are specified for these two equations (i.e., $M=N=6$ ). With these lag specifications, all the models estimated have shown satisfactory statistical properties in addressing serial correlation.

The bounds test can be applied after the maximum lags are specified. As reported in Table 2, cointegrating relations can be established for 9 out of the 12 equations. Three equations are within the inclusive regions: coniferous roundwood from Canada and nonconiferous lumber from Russia and Indonesia. To determine if the variables in these equations are cointegrated at the optimal lags, the ARDL model is estimated for them, and then the bounds test is conducted at the selected optimal lags for each pair. All the F-statistics improve 
Table 2. The Bounds Test for Cointegrating Relation and Optimal Lag Selection by Product and Source

\begin{tabular}{llllllll}
\hline \hline & & \multicolumn{2}{c}{ Lags } & & \multicolumn{2}{c}{ Bounds Test } & \\
Product & Supplier & Maximum & Optimal & & Maximum Lag & Optimal Lag & Cointegrated \\
\hline 440320 & & & & & & \\
& Russia & 4 & $(1,3,0,1,0,2)$ & & $4.52^{* * *}$ & $5.41^{* * *}$ & Yes \\
& New Zealand & 6 & $(6,1,6,2,2,0)$ & $8.87^{* * *}$ & $12.52^{* * *}$ & Yes \\
& United States & 4 & $(3,0,0,0,0,0)$ & $4.28^{* * *}$ & $4.83^{* * *}$ & Yes \\
& Canada & 4 & $(2,0,0,1,0,0)$ & 2.53 & $4.26^{* * *}$ & Yes \\
440710 & & & & & & & \\
& Canada & 4 & $(2,0,3,0,0,0)$ & $5.17^{* * *}$ & $7.58^{* * *}$ & Yes \\
& Russia & 4 & $(2,0,0,0,0,3)$ & $3.91^{* *}$ & $5.66^{* * *}$ & Yes \\
& United States & 4 & $(1,1,0,0,0,0)$ & $4.53^{* * *}$ & $8.43^{* * *}$ & Yes \\
& Chile & 4 & $(3,4,0,4,1,0)$ & $3.68^{* *}$ & $3.88^{* *}$ & Yes \\
& & & & & & & \\
& Thailand & 4 & $(4,0,4,2,4,3)$ & $5.22^{* * *}$ & $6.28^{* * *}$ & Yes \\
& United States & 6 & $(5,2,6,0,5,3)$ & $3.46^{* *}$ & $3.51^{* *}$ & Yes \\
& Russia & 4 & $(4,0,0,0,0,1)$ & 2.94 & $3.20^{*}$ & Yes \\
& Indonesia & 4 & $(2,0,1,1,0,0)$ & 1.97 & 2.50 & Uncertain \\
\hline \hline
\end{tabular}

Notes: The maximum lag is set at 6 or 4 for all the dependent variable and dynamic independent variables. The optimal lag order is selected based on the Akaike information criterion value. For the model specified in this study (i.e., five dynamic regressors, restricted intercept, and no trend), the asymptotic critical value bounds for the $F$-statistic are $(2.08,3.00)$ for the $10 \%$ level of significance, $(2.39,3.38)$ for the $5 \%$ level, and $(3.05,4.15)$ for the $1 \%$ level (Pesaran, Shin, and Smith, 2001). The bounds test is conducted twice for each product-supplier pair, using the maximum lag or optimal lags from the model fit. Asterisks $\left(^{* * *}\right.$, **, and ${ }^{*}$ ) denote significance at the $1 \%, 5 \%$, and $10 \%$ level, respectively.

with the optimal lags. However, for the nonconiferous lumber imports from Indonesia, the $F$-statistic of 2.50 is still in the inconclusive zone. The restricted error correction model is constructed for this product pair. The error correction term is significantly negative, which confirms that the cointegrating relation does exist.

After the cointegrating relations among the economic variables are established, the next step is to estimate the ARDL model with various combinations of the maximum lag specifications and select the optimal fit. The best model is determined by the lowest AIC value. In Figure 2, the lag selection for the coniferous roundwood export from New Zealand is presented as an example. The top 20 model specifications are sorted by the corresponding AIC values. In this particular case, the optimal lags are $(6,1,6,2,2,0)$-that is, 6 lags for the price of coniferous roundwood from New Zealand, 1 for the quantity, 6 for the exchange rate of Russia, 2 for the exchange rate of the United States, 2 for the exchange rate of Canada, and no lag for the demand shifter. For other productsupplier pairs, the best optimum lags vary by product and suppliers, as presented together in Table 2. 


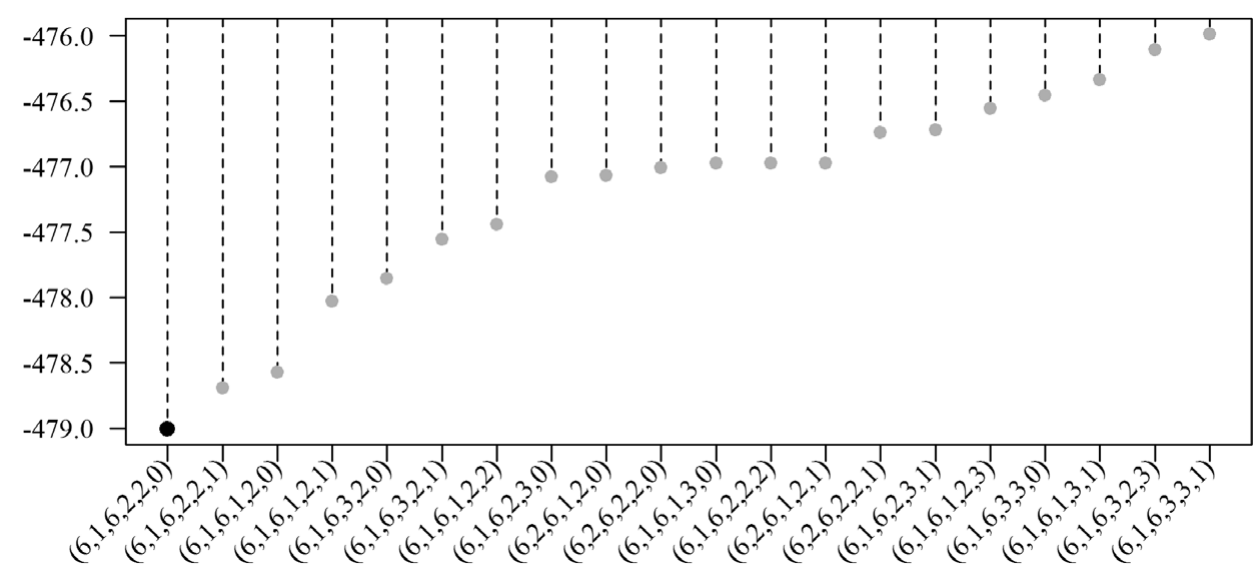

Figure 2. The Akaike Information Criterion Values of Different Autoregressive Distributed Lag Model Specifications for the Import of Coniferous Roundwood by China from New Zealand (the final selected model is the first one, denoted with the black dot)

In the end, the optimal ARDL model for each of the 12 product-supplier pairs can be estimated by using the optimal lags. The estimates per se have limited values and will be used to extract long-run and short-run inverse residual demand elasticities for interpretation later. In Table 3, the estimates of the coefficients in the ARDL model for the coniferous roundwood exports from Russia and New Zealand are presented for illustration.

\subsection{Long-Run and Short-Run Inverse Residual Demand Elasticity Estimates}

The long-run and short-run inverse residual demand elasticities can be computed using the estimates from the best-fitted ARDL model. The outputs for the import quantity variable reveal and measure the market power of individual supplying countries. These estimates are the key result, as reported in Tables 4 and 5.

Specifically, Table 4 contains the long-run inverse residual demand elasticities. In the import market of coniferous roundwood, two of the four countries demonstrate some small amount of market power. The significant estimates are -0.09 for Russia and -0.07 for New Zealand. They are the top two suppliers of coniferous roundwood to China. The United States and Canada have been exporting an increasing amount of roundwood to China in recent years. However, no market power for these two countries is found through the analysis. For the coniferous lumber market, three countries have significant estimates and market power: -0.08 for Canada, -0.49 for the United States, and -0.06 for Chile. The only country among the top four suppliers without any market power is Russia. In nonconiferous lumber market, two of the four countries have some market power, -0.17 for Thailand and -1.69 for Indonesia, 
Table 3. Selected Results from the Best-Fitted Autoregressive Distributed Lag Model for Coniferous Roundwood Import by China

\begin{tabular}{|c|c|c|c|c|c|}
\hline \multicolumn{3}{|c|}{ Russia } & \multicolumn{3}{|c|}{ New Zealand } \\
\hline Variable & Estimate & $t$ - Ratio & Variable & Estimate & $t$-Ratio \\
\hline Constant & $0.60^{* * *}$ & 2.79 & (Intercept) & $2.09^{* * *}$ & 4.69 \\
\hline$p_{\text {russ }, t-1}$ & $0.85^{* * *}$ & 24.50 & $p_{\text {new } z, t-1}$ & $0.62^{* * *}$ & 10.04 \\
\hline$q_{\text {russ }, t}$ & -0.03 & -0.97 & $p_{\text {new } z, t-2}$ & -0.07 & -1.03 \\
\hline$q_{\text {russ }, t-1}$ & -0.03 & -0.98 & $p_{\text {new } z, t-3}$ & $0.17^{* *}$ & 2.36 \\
\hline$q_{r u s s, t-2}$ & $0.07^{* *}$ & 2.33 & $p_{\text {newz }, t-4}$ & $-0.27^{* * *}$ & -3.81 \\
\hline$q_{\text {russ, } t-3}$ & -0.02 & -1.55 & $p_{\text {new } z, t-5}$ & $0.22^{* * * *}$ & 3.16 \\
\hline$w_{\text {new } z, t}$ & $-0.07^{*}$ & -1.78 & $p_{\text {new } z, t-6}$ & $-0.14^{* * *}$ & -2.50 \\
\hline$w_{\text {unit }, t}$ & $0.71^{* *}$ & 2.06 & $q_{n e w z, t}$ & $-0.07^{* * *}$ & -3.93 \\
\hline$w_{\text {unit }, t-1}$ & $-0.75^{* *}$ & -2.21 & $q_{\text {new } z, t-1}$ & $0.04^{* * *}$ & 2.72 \\
\hline$w_{\text {cana }, t}$ & $0.22^{* * *}$ & 3.57 & $w_{\text {russ, }, t}$ & $-0.44^{* * *}$ & -2.88 \\
\hline$z_{t}$ & 0.01 & 0.14 & $w_{\text {russ }, t-1}$ & $0.92^{* * *}$ & 3.82 \\
\hline$z_{t-1}$ & $0.13^{* * *}$ & 2.64 & $w_{\text {russ }, t-2}$ & $-0.91^{* * *}$ & -3.65 \\
\hline$z_{t-2}$ & $-0.11^{* * *}$ & -2.81 & $w_{\text {russ, } t-3}$ & 0.23 & 0.94 \\
\hline$R^{2}$ & 0.94 & & $w_{\text {russ, } t-4}$ & -0.18 & -0.69 \\
\hline \multirow[t]{11}{*}{ Durbin-Watson } & 2.10 & 0.57 & $w_{\text {russ, } t-5}$ & $0.82^{* * *}$ & 3.39 \\
\hline & & & $w_{\text {russ, } t-6}$ & $-0.52^{* * *}$ & -3.62 \\
\hline & & & $w_{\text {unit }, t}$ & $3.84^{* * *}$ & 4.12 \\
\hline & & & $w_{\text {unit }, t-1}$ & $-2.86^{* *}$ & -2.03 \\
\hline & & & $w_{\text {unit }, t-2}$ & -1.30 & -1.49 \\
\hline & & & $w_{\text {cana }, t}$ & -0.06 & -0.16 \\
\hline & & & $w_{\text {cana }, t-1}$ & -0.56 & -1.05 \\
\hline & & & $w_{\text {cana }, t-2}$ & $1.29^{* * *}$ & 3.49 \\
\hline & & & $z_{t}$ & 0.05 & 1.32 \\
\hline & & & $R^{2}$ & 0.81 & \\
\hline & & & Durbin-Watson & 1.88 & 0.26 \\
\hline
\end{tabular}

Notes: The value beside the Durbin-Watson statistic is the $P$-value. Asterisks $(* * *$, **, and *) denote significance at the $1 \%, 5 \%$, and $10 \%$ level, respectively. Country names are used in the subscripts of several variables (i.e., Russia [russ], New Zealand [newz], the United States [unit], and Canada [cana]).

whereas the elasticities for the United States and Russia are insignificant. Across the three product categories, the estimates have the largest value in the case of nonconiferous lumber imports from Indonesia $(-1.69)$, followed by coniferous lumber imports from the United States $(-0.49)$. Overall, the magnitude of market power for lumber products is larger than that for the roundwood products.

In Table 4, the estimates from the OLS are also included for comparison. The main difference between the OLS and ARDL approaches is the consideration of time-series properties and the inclusion of lagged variables in the latter. Although some results are similar, a few product-supplier pairs do show dramatic changes in either the magnitude or significance level. For example, in the coniferous roundwood market, all four countries have shown some market power in the OLS model, but the $t$-values in the ARDL model become much less significant 
Table 4. Long-Run Inverse Residual Demand Elasticities by Product and Supplier from the Ordinary Least Square (OLS) and Autoregressive Distributed Lag (ARDL) Estimations

\begin{tabular}{|c|c|c|c|c|c|}
\hline \multirow[b]{2}{*}{ Product } & \multirow[b]{2}{*}{ Supplier } & \multicolumn{2}{|c|}{ OLS } & \multicolumn{2}{|c|}{ ARDL } \\
\hline & & Estimate & $t$-Value & Estimate & $t$-Value \\
\hline \multicolumn{6}{|l|}{440320} \\
\hline & Russia & $-0.15^{* * *}$ & -12.20 & $-0.09^{* *}$ & -1.98 \\
\hline & New Zealand & $-0.11^{* * *}$ & -9.83 & $-0.07^{* * *}$ & -3.83 \\
\hline & United States & $-0.07^{* * *}$ & -4.08 & -0.05 & -1.20 \\
\hline & Canada & $-0.29^{* * *}$ & -6.79 & -0.19 & -1.40 \\
\hline \multicolumn{6}{|l|}{440710} \\
\hline & Canada & $-0.05^{* * *}$ & -3.79 & $-0.08^{* * *}$ & -2.87 \\
\hline & Russia & -0.01 & -0.81 & -0.00 & -0.00 \\
\hline & United States & $-0.48^{* * *}$ & -8.83 & $-0.49^{* * *}$ & -4.08 \\
\hline & Chile & $-0.06^{* * *}$ & -6.14 & $-0.06^{* *}$ & -2.27 \\
\hline \multicolumn{6}{|l|}{440799} \\
\hline & Thailand & $-0.21^{* * *}$ & -10.75 & $-0.17^{* * *}$ & -2.51 \\
\hline & United States & $0.12^{* * *}$ & 4.11 & 0.10 & 0.96 \\
\hline & Russia & $-0.16^{* * *}$ & -2.76 & -0.11 & -0.61 \\
\hline & Indonesia & $-0.99^{* * *}$ & -6.37 & $-1.69^{* * *}$ & -2.57 \\
\hline
\end{tabular}

Note: Asterisks $\left({ }^{* * *},{ }^{* *}\right.$, and $\left.{ }^{*}\right)$ denote significance at the $1 \%, 5 \%$, and $10 \%$ level, respectively.

(e.g., -4.08 to -1.20 for the United States). In the nonconiferous lumber market, the estimate for Indonesia increases from -0.99 in the OLS model to -1.69 in the ARDL model, revealing the presence of much bigger market power after considering the lagged effects.

The short-run dynamics in the import market is shown through the restricted error correction model. The values for the inverse residual demand elasticity and error correction terms are the key results, and they are presented in Table 5. The patterns are broadly consistent with these in the long run. All the estimates have the expected negative signs, except that for coniferous roundwood imports from Russia. Note Russia does show some marginally significant market power at lag two (i.e., the estimated value of -0.02 and the $t$-value of -1.55 ). For these significant estimates, most of them have smaller values than the longrun estimates in Table 4, which is within expectation. Similar to the pattern of the long-run estimates, the supplying countries have larger market power in the lumber market than in the roundwood market. The biggest value is -0.35 for coniferous lumber imports from the United States, followed by -0.23 for nonconiferous lumber imports from Indonesia.

In the context of the restricted error correction model, the magnitude of the error correction term reflects the speed of adjustment in response to any market disequilibrium. All the estimates are negative and highly significant at the $1 \%$ level of significance. The responding rates vary by product and source. Across the three product categories, the response time for the top suppliers on average 
Table 5. Short-Run Inverse Residual Demand Elasticities and Error Correction Terms Calculated from the Restricted Error Correction Models

\begin{tabular}{|c|c|c|c|c|c|c|c|}
\hline \multirow[b]{2}{*}{ Product } & \multirow[b]{2}{*}{ Supplier } & \multicolumn{3}{|c|}{$\Delta q_{t-n}$} & \multicolumn{3}{|c|}{$E C_{t-1}$} \\
\hline & & $\operatorname{Lag}(n)$ & Estimate & $t$-Value & Estimate & $t$-Value & Time \\
\hline \multicolumn{8}{|l|}{440320} \\
\hline & Russia & 0 & -0.03 & -0.97 & $-0.15^{* * *}$ & -4.47 & 6.7 \\
\hline & & 1 & $0.05^{*}$ & 1.81 & & & \\
\hline & & 2 & -0.02 & -1.55 & & & \\
\hline & New Zealand & 0 & $-0.07^{* * *}$ & -3.93 & $-0.48^{* * *}$ & -8.08 & 2.1 \\
\hline & United States & 0 & -0.02 & -1.15 & $-0.33^{* * *}$ & -5.55 & 3.0 \\
\hline & Canada & 0 & -0.03 & -1.28 & $-0.17^{* * *}$ & -4.70 & 5.9 \\
\hline \multicolumn{8}{|l|}{440710} \\
\hline & Canada & 0 & $-0.03^{* * *}$ & -2.94 & $-0.42^{* * *}$ & -6.95 & 2.4 \\
\hline & Russia & 0 & -0.00 & -0.00 & $-0.32^{* * *}$ & -5.68 & 3.1 \\
\hline & United States & 0 & $-0.35^{* * *}$ & -4.34 & $-0.35^{* * *}$ & -7.31 & 2.9 \\
\hline & Chile & 0 & -0.01 & -1.06 & $-0.28^{* * *}$ & -4.65 & 3.6 \\
\hline & & 1 & $-0.03^{* *}$ & -2.03 & & & \\
\hline & & 2 & $-0.07^{* * *}$ & -4.15 & & & \\
\hline & & 3 & $-0.05^{* * *}$ & -3.94 & & & \\
\hline \multicolumn{8}{|l|}{440799} \\
\hline & Thailand & 0 & $-0.03^{* *}$ & -1.98 & $-0.20^{* * *}$ & -4.11 & 5.0 \\
\hline & United States & 0 & 0.24 & 0.90 & $-0.21^{* * *}$ & -3.93 & 4.8 \\
\hline & & 1 & -0.44 & -1.63 & & & \\
\hline & Russia & 0 & -0.02 & -0.60 & $-0.21^{* * *}$ & -4.30 & 4.8 \\
\hline & Indonesia & 0 & $-0.23^{* * *}$ & -2.47 & $-0.13^{* * *}$ & -3.81 & 7.7 \\
\hline
\end{tabular}

Note: Time is measured in months (e.g., $1 / 0.15=6.7$ months). Asterisks $\left({ }^{* * *},{ }^{* *}\right.$, and $\left.{ }^{*}\right)$ denote significance at the $1 \%, 5 \%$, and $10 \%$ level, respectively.

is $4.4,3.0$, and 5.6 months for the coniferous roundwood, coniferous lumber, and nonconiferous lumber, respectively. Individually, the shortest response time is 2.1 months for coniferous roundwood imports from New Zealand, and the longest response time is 7.7 months for nonconiferous lumber imports from Indonesia.

\section{Discussion and Summary}

In recent years, China has spent more than 13 billion U.S. dollars on an annual basis to import roundwood and lumber products worldwide to meet its timber demand from domestic and export-oriented manufacturing activities. Suppliers of these wood products include neighboring countries in Southeast Asia and Russia, but also include countries in America, such as Canada and the United States. Despite the large trading volume, the competition intensity among these supplying countries in the import market of China has received limited investigation in the past. In this study, the elasticity of inverse residual import demand is estimated to measure the degree of market power for three major wood products: coniferous roundwood, coniferous lumber, and nonconiferous 
lumber. The top four supplying countries in each of the three markets are included in the analysis. Time-series properties of the trade data are considered through the ARDL model and the associated bounds test for cointegration. The analysis reveals several interesting findings of the imperfect market competition.

Overall, the suppliers in the lumber market have possessed larger market power than those in the roundwood market, which is true in both the long term and short term. This may be mainly caused by the differences between these two types of wood products and the availability of potential suppliers in the import market. In general, wood products can differ greatly in the degree of transformation on fiber, with the least on roundwood, more on lumber products, and the most on wood-based panels and furniture products. Lumber products are easier than roundwood products to store, handle, and transport, giving suppliers more flexibility and control in marketing their products. In addition, several of the leading roundwood exporters in the global market are countries with limited wood processing capacity, and exporting raw materials like roundwood is their primary choice. Thus, China has more diversification of supplying sources in the roundwood market than in the lumber market. All these factors together can result in a stronger presence of market power by suppliers in the lumber market.

The magnitude of the market power measure is small in most cases, with the absolute values being bigger than 0.10 for only 3 out of 12 product-supplier pairs in the long term. In particular, the absolute values for coniferous lumber of the United States $(-0.49)$ and nonconiferous lumber of Indonesia $(-1.69)$ are much larger than the others. A close examination of the import data reveals that a large variation of lumber values over the study period has occurred in both cases, resulting in some prominent peaks and bottoms (Figure 1). They may be associated with changes in trade policy, product differentiation and heterogeneity (especially for lumber), or domestic demand fluctuation in those individual supplying countries. The changes may give those suppliers more control and influence over the trade and, consequentially, be responsible for the presence of market power.

The correlations between the market power measures and market shares seem low or at most moderate. In general, the shares of supplying countries in a market are just an indication of the presence of market power. In the coniferous roundwood market, the top two suppliers (i.e., Russia and New Zealand) demonstrate some market power, but the other two do not (i.e., the United States and Canada), indicating some moderate correlation between the measures of market power and share. In the two lumber markets, the correlation is much lower. The United States in the coniferous lumber market and Indonesia in the nonconiferous lumber market have less than $10 \%$ of the market share, but they have much larger market power than other countries in the market. Their market shares indeed experienced more fluctuations during the period. Thus, besides the level of market shares, the volatility can be another indicator of potential market power. 
The imperfect market structure revealed through the analysis in this study can have implications to active participants in the global wood products market for their trade policy designs. Exporting roundwood, not lumber products, is usually perceived as reducing the availability of raw materials for the domestic wood processing industry and decreasing opportunities for income growth in forest-dependent communities. Thus, many countries have adopted restrictive trade policies (e.g., a ban or tariff on roundwood trade) to encourage a shift in exports from unprocessed roundwood to value-added forest products. For example, Russia has implemented various tariff schedules on roundwood exports to protect its domestic industry in recent years. Other countries, including Canada, Indonesia, and the United States, also have restrictive policies in dealing with roundwood exports. Given that roundwood exporting countries have very limited influence over price in the global market, countries with abundant forest resources can have policies that provide more supports to the domestic wood processing industry and thus encourage the export of lumber products.

Finally, it should be noted that some questions related to the research issue in this study are still unanswered. The research methods adopted in this study can detect potential market power and measure the intensity of competition in a market at the macrolevel of the whole industry. However, the research methods are unable, for instance, to reveal the possible variation of market power over time, identify the exact sources of the market power, and evaluate the welfare impact of the market power on trading partners. In addition, given China's large imports of some products, it is unclear whether China has any buying power in the international market of wood products. Nevertheless, this study can be a good foundation for future studies. For example, some of the findings can be integrated into forest sector modeling such as the global forests product model (Buongiorno et al., 2003) to examine the impact of market power possessed by individual trading partners. Similar research also can be conducted to have a closer examination of the cost structure of different supplying countries or trade policies for specific wood products when data are available.

\section{References}

Baek, J., W.W. Koo, and K. Mulik. "Exchange Rate Dynamics and the Bilateral Trade Balance: The Case of U.S. Agriculture." Agricultural and Resource Economics Review 38,2(2009):213-28.

Baker, J.B., and T.F. Bresnahan. "Estimating the Residual Demand Curve Facing a Single Firm." International Journal of Industrial Organization 6,3(1988):283-300.

Banerjee, A., J. Dolado, J.W. Galbraith, and D.F. Hendry. Co-Integration, Error Correction, and the Econometric Analysis of Non-Stationary Data. New York: Oxford University Press, 1993.

Buongiorno, J., S. Zhu, D. Zhang, J. Turner, and D. Tomberlin. The Global Forest Products Model. San Diego, CA: Academic Press, 2003. 
Chang, W.-Y., and C. Gaston. “A Trade Flow Analysis of the Global Softwood Log Market: Implications of Russian Log Export Tax Reduction and New Zealand Log Production Restriction." Forestry 89,1(2016):20-35.

Engle, R.F., and C.W.J. Granger. "Co-Integration and Error Correction: Representation, Estimation, and Testing.” Econometrica 55,2(1987):251-76.

Fedoseeva, S. "(A)symmetry, (Non)linearity and Hysteresis of Pricing-to-Market: Evidence from German Sugar Confectionery Exports.” Journal of Agricultural and Food Industrial Organization 11,1(2013):69-85.

Felt, M.-H., J.-P. Gervais, and B. Larue. "Market Power and Import Bans: The Case of Japanese Pork Imports.” Agribusiness 27,1(2011):47-61.

Food and Agriculture Organization of the United Nations. Forestry Statistics. Internet site: http://faostat.fao.org (Accessed May 1, 2016).

Getnet, K., W. Verbeke, and J. Viaene. "Modeling Spatial Price Transmission in the Grain Markets of Ethiopia with an Application of ARDL Approach to White Teff." Agricultural Economics 33,S3(2005):491-502.

Global Trade Information Services. World Trade Atlas Database. Internet site: http://www. gtis.com (Accessed March 1, 2016).

Goldberg, P.K., and M.M. Knetter. "Measuring the Intensity of Competition in Export Markets.” Journal of International Economics 47,1(1999):27-60.

Henneberry, S.R., and J.E. Mutondo. "Agricultural Trade among NAFTA Countries: A Case Study of U.S. Meat Exports.” Review of Agricultural Economics 31,3(2009):424-45.

International Monetary Fund. International Financial Statistics. Internet site: http://www.imf. org (Accessed August 8, 2016).

Kennedy, P. A Guide to Econometrics. 6th ed. New York: Blackwell, 2008.

National Bureau of Statistics of China. Economic Database. Internet site: http://www.stats. gov.cn (Accessed August 8, 2016).

Niquidet, K., and J. Tang. "Elasticity of Demand for Canadian Logs and Lumber in China and Japan." Canadian Journal of Forest Research 43,12(2013):1196-202.

Pesaran, B., and M.H. Pesaran. Time Series Econometrics Using Microfit 5.0. New York: Oxford University Press, 2009.

Pesaran, M.H., Y. Shin, and R.J. Smith. "Bounds Testing Approaches to the Analysis of Level Relationships." Journal of Applied Econometrics 16,3(2001):289-326.

R Development Core Team. R: A Language and Environment for Statistical Computing. Internet site: http://www.r-project.org (Accessed April 25, 2017).

Reed, M.R., and S.H. Saghaian. "Measuring the Intensity of Competition in the Japanese Beef Market." Journal of Agricultural and Applied Economics 36,1(2004):113-21.

Song, B., M.A. Marchant, M.R. Reed, and S. Xu. "Competitive Analysis and Market Power of China's Soybean and Import Market." International Food and Agribusiness Management Review 12,1(2009):21-41.

Sun, C. "Recent Growth in China's Roundwood Import and Its Global Implications." Forest Policy and Economics 39,1(2014):43-53.

Turner, J., F. Maplesden, B. Walford, and S. Jacobi. "Tariff and Non-Tariff Barriers to New Zealand's Exports of Wood-Based Products to China." New Zealand Journal of Forestry 50,1(2005):27-33.

Xie, J., and D. Zhang. "Imperfect Competition and Structural Changes in the US Salmon Import Market." Marine Resource Economics 29,4(2014):375-89.

Zhang, D., and Y. Li. "Forest Endowment, Logging Restrictions, and China's Wood Products Trade." China Economic Review 20,1(2009):46-53. 


\section{Appendix}

\section{Technical Details for the Autoregressive Distributed Lag (ARDL) Framework}

Some technical details related to the key steps in the ARDL framework are presented here. In the second step, the bounds test (Pesaran, Shin, and Smith, 2001) is based on the unrestricted error correction model, which is transformed from the general ARDL model in equation (2):

$$
\Delta y_{t}=-\sum_{m=1}^{M-1} \tilde{\gamma}_{m} \Delta y_{t-m}+\sum_{j=1}^{J} \sum_{n=0}^{N_{j}-1} \tilde{\beta}_{j, n} \Delta x_{j, t-n}-\rho y_{t-1}-\zeta-\sum_{j=1}^{J} \delta_{j} x_{j, t-1}+v_{t},
$$

where $\Delta$ denotes the first difference; $v$ is the error term; $\tilde{\gamma}, \tilde{\beta}, \rho, \zeta$, and $\delta$ are coefficients to be estimated; and other symbols remain the same. This transformation does not depend on any assumption, and it just involves some simple combinations of terms.

The bounds test for the existence of a cointegrating relation among $y$ and $x$ is an $F$-test for the joint significance of lagged level variables with the null hypothesis of the nonexistence of a long-run relationship: $\rho=\delta_{1}=\ldots=\delta_{J}=0$. Equation $(\mathrm{A}-1)$ is a linear model, so the F-statistic can be easily computed. Pesaran, Shin, and Smith (2001) generated two sets of critical bounds for the F-test. The lower bound critical values assume all variables are stationary [i.e., I (0)], and the upper bound critical values assume that all variables are integrated of order one [i.e., I (1)]. If the calculated F-statistic exceeds upper critical bound, the null hypothesis of no cointegration among variables can be rejected. If the calculated F-statistic falls below the lower bound, the null hypothesis is accepted. If the computed F-statistic is between the upper and lower bounds, then the decision is inconclusive, and the order of integration of the explanatory variables must be known for any conclusion. In that situation, if the variables are I $(0)$, then the variables are cointegrated on the basis of the lower bound; conversely, if the variables are I (1), then the variables are not cointegrated on the basis of the upper bound.

In the third step, the ARDL model with the best fit will be identified. Although the ARDL model can be estimated anytime, this step usually is implemented after the long-run cointegrating relation is established by the bounds test. Equation (2) can be estimated with a set of lag values. To select the best-fitted ARDL model, all possible combinations of $M$ and $N$ are considered, with a total of $M\left(1+N_{1}\right)(1+$ $\left.N_{2}\right) \ldots\left(1+N_{J}\right)$. The number of regressions can become very large when the number of independent variables and lags grows. For example, given $K=5$ in equation (2), the total number of regressions is 12,500 when $M=N=4$, or 100,842 when $M=$ $N=6$. All the models should be estimated over the same period to be comparable, as determined by the maximum lag. Typical criteria used for the selection of the best fit include the Bayesian information criterion, Akaike information criterion (AIC), and the adjusted $R^{2}$. In this study, the model with the optimal lags is selected with the lowest AIC. After the optimal lags are chosen for each variable, the ARDL model is estimated again. The final model can be assessed with several criteria (e.g., DurbinWatson statistic for serial correlation). 
In the fourth step, the long-run and short-run inverse residual demand elasticities from the best-fitted ARDL model are calculated. The long-run values can be computed as follows:

$$
\hat{\theta}_{j}=\frac{\sum_{n=0}^{N_{j}} \hat{\beta}_{j, n}}{1-\sum_{m=1}^{M} \hat{\gamma}_{m}},
$$

where $\hat{\gamma}$ and $\hat{\beta}$ are the estimates of the best-fitted ARDL model from equation (2). Thus, the long-run elasticity for an individual independent variable is calculated from the estimated coefficients of the lagged independent variables, adjusted by the coefficients of the lagged dependent variables. Note that the calculation for both dynamic and fixed regressors is accommodated in the formula because the lag for fixed regressors is zero (i.e., $N_{j}=0$ ). The standard errors for the computed long-run elasticities are calculated by the delta method.

The short-run parameters are calculated using the restricted error correction model. If there is a long-run cointegrating relation between the variables (as supported by the bounds test), then an error correction representation exists. To ensure the convergence of the dynamics to long-run equilibrium, the sign of the lagged error correction term coefficient should be negative and statistically significant. The error correction representation of the ARDL model can be obtained by transforming the ARDL model of equation (2) in terms of the lagged levels and the first differences of the variables:

$$
\Delta y_{t}=-\sum_{m=1}^{M-1} \gamma_{m}^{*} \Delta y_{t-m}+\sum_{j=1}^{J} \sum_{n=0}^{N_{j}-1} \beta_{j, n}^{*} \Delta x_{j, t-n}-\hat{\phi} E C_{t-1},
$$

where $\gamma_{m}^{*}=\sum_{k=m+1}^{M} \hat{\gamma}_{k}, \beta_{j, n}^{*}=\sum_{k=n+1}^{N_{i}} \hat{\beta}_{j, k}, \hat{\phi}=1-\sum_{m=1}^{M} \hat{\gamma}_{m}$, and $E C_{t}=y_{t}-\hat{\alpha}-$ $\sum_{j=1}^{J} \hat{\theta}_{j} x_{j, t}$. Note that the model is not estimated, but the coefficients are computed with the estimates of $\hat{\gamma}_{m}$ and $\hat{\beta}_{j, n}$ from the best-fitted ARDL model (Pesaran and Pesaran, 2009). The standard errors of the coefficients are calculated by the delta method. 